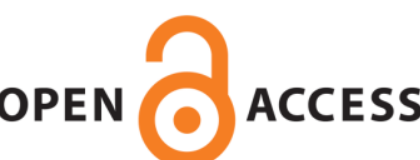

\title{
Investigation of high-temperature ultrasonic transducer design using lithium niobate piezocomposite
}

Kirk, Katherine; Hou, Ruozhou ; Schmarj, Nicole ; Pragada, Naga Mahesh ; Torbay, Louis ; Hutson, David

Published in:

Insight - Non-destructive Testing and Condition Monitoring

DOI:

10.1784/insi.2015.57.4.193

Published: 01/04/2015

Document Version

Publisher's PDF, also known as Version of record

Link to publication on the UWS Academic Portal

Citation for published version (APA):

Kirk, K., Hou, R., Schmarj, N., Pragada, N. M., Torbay, L., \& Hutson, D. (2015). Investigation of hightemperature ultrasonic transducer design using lithium niobate piezocomposite. Insight - Non-destructive Testing and Condition Monitoring, 57(4), 193-199. https://doi.org/10.1784/insi.2015.57.4.193

\section{General rights}

Copyright and moral rights for the publications made accessible in the UWS Academic Portal are retained by the authors and/or other copyright owners and it is a condition of accessing publications that users recognise and abide by the legal requirements associated with these rights.

Take down policy

If you believe that this document breaches copyright please contact pure@uws.ac.uk providing details, and we will remove access to the work immediately and investigate your claim. 


\title{
Investigation of high-temperature ultrasonic transducer design using lithium niobate piezocomposite
}

\author{
K J Kirk, R Hou, N Schmarje, N M Pragada, L Torbay and D Hutson
}

\begin{abstract}
The design and fabrication of lithium niobate piezocomposite transducers aims to achieve high-temperature ultrasonic NDT measurements at $400^{\circ} \mathrm{C}$. In this paper, three aspects are investigated: exploring design parameters at room temperature by a comparison of experimental and modelled results for lithium niobate piezocomposites with an epoxy matrix; high-temperature electromechanical testing of lithium niobate piezocomposites with a cement matrix; and fabrication and testing of a high-temperature transducer operating at $400^{\circ} \mathrm{C}$ for defect detection.

The piezocomposites were made with a 1-3 structure using a y/36-cut lithium niobate single-crystal material. The typical piezocomposite thickness was $1 \mathrm{~mm}$, with a pillar width of 0.4-0.8 $\mathrm{mm}$, a kerf width of $0.5 \mathrm{~mm}$, a volume fraction of lithium niobate of 30-40\% and a pillar aspect ratio (pillar height to pillar width) ranging from 1 to 6 . The operating frequency of the samples was between $1 \mathrm{MHz}$ and $4 \mathrm{MHz}$.

The results of the lithium niobate piezocomposite with an epoxy matrix and pillar aspect ratios of 3, 4 and 6 indicated that a high coupling coefficient $k_{\text {t }}$ should be achievable, even with a low pillar aspect ratio. The piezocomposite material was heated in air to $400-500^{\circ} \mathrm{C}$ over several thermal cycles and showed good stability of the electromechanical impedance spectrum. A $13 \times 13 \mathrm{~mm}^{2}$ transducer with an operating frequency of $3 \mathrm{MHz}$ was used to demonstrate the detection of an artificial defect in a steel block using a high-temperature couplant on a hot plate at $400^{\circ} \mathrm{C}$.
\end{abstract}

\section{Introduction}

Ultrasonic transducers and arrays for NDT commonly use piezoelectric ceramic PZT (lead zirconate titanate) as the active material and often incorporate epoxy for bondlines, backing layers and as a passive material in piezocomposites. Therefore, transducers based on these materials cannot usually withstand high temperatures above $150^{\circ} \mathrm{C}$ unless actively cooled (although it has then been possible to obtain scanned measurements up to $\left.400^{\circ} \mathrm{C}^{[1]}\right)$. Other solutions have been sought, including non-contact measurements not requiring couplant (optical or EMAT ${ }^{[2]}$ ), hightemperature resistant piezoelectric materials such as bismuth titanate $^{[3,4]}$ or new advanced high-temperature materials ${ }^{[5]}$.

The high-temperature piezoelectric material lithium niobate has been used to make high-temperature transducers for ultrasonic testing at $400^{\circ} \mathrm{C}$ since $1989^{[6]}$. Lithium niobate piezocomposites were subsequently devised ${ }^{[7]}$ in order to obtain improved mechanical and ultrasonic properties compared to an undiced plate of material. Advantages include the elimination of plate modes, better resistance to cracking and lower $Q_{m}$.

The Curie temperature, $T_{c}$, of lithium niobate is $1210^{\circ} \mathrm{C}$ and the material is generally regarded as usable up to half $T_{c}$, ie $600^{\circ} \mathrm{C}$, although very high-temperature use of lithium niobate in ultrasonic testing up to $1000^{\circ} \mathrm{C}$ has recently been reported ${ }^{[8]}$. In another example of high-temperature material development, lithium niobate has been used as the basis for a new high-temperature piezoceramic of the family $\mathrm{Li}_{(1-x)} \mathrm{Na}_{\mathrm{x}} \mathrm{NbO}_{3}$ for operation at $800^{\circ} \mathrm{C}^{[9]}$. The intention was to produce a ceramic material with a single poling direction, which was stabilised against oxygen loss at a high temperature by the addition of sodium.

We have developed high-temperature ultrasonic transducers made from lithium niobate 1-3 piezocomposites (ie pillars of piezoelectric material embedded in a passive matrix). We previously demonstrated the use of lithium niobate piezocomposite in non-destructive testing applications. Experiments included: phased array operation at $2 \mathrm{MHz}$ using a commercial array controller ${ }^{[10,11]}$, excitation of individual elements of a lithium niobate piezocomposite flexible array up to $250^{\circ} \mathrm{C}^{[12]}$ and high-temperature detection of acoustic emission test signals in the frequency range of $0.1-1 \mathrm{MHz}^{[13]}$.

In this paper, we look at the design and fabrication of 1-3 piezocomposites made using $y / 36^{\circ}$-cut lithium niobate, which has the largest electromechanical coupling coefficient available from lithium niobate for bulk waves. In the first part, we made lithium niobate piezocomposites using epoxy filler for comparison with results from established modelling techniques and in order to obtain basic design rules, like those used for PZT/epoxy piezocomposites. These piezocomposites were tested at room temperature. In the second part, we made lithium niobate piezocomposites with cement filler, which were characterised by impedance measurements and pulse-echo testing at high temperatures of $400-500^{\circ} \mathrm{C}$, with up to five thermal cycles. Following this, in the third part of the work we carried out fabrication and testing of a high-temperature transducer operating at $400^{\circ} \mathrm{C}$, fluid-coupled to a test-block using high-temperature couplant.

Submitted 18.03.14 / Accepted 20.10.14

Katherine J Kirk, Naga Mahesh Pragada, Louis Torbay and David Hutson are with the School of Engineering and Computing, University of the West of Scotland, Paisley Campus, Paisley, Renfrewshire PA1 2BE, UK. Tel: +44 (0)141 848 3409; Fax: +44 (0)141 848 3663; Email: katherine.kirk@uws.ac.uk

Ruozhou Hou is with the School of Chemical Engineering and Analytical Science, University of Manchester, Oxford Road, Manchester M13 9PL, UK.

Nicole Schmarje is with IntelligeNDT Systems \& Services GmbH, AREVA NDE Solutions, Paul-Gossen-Str 100, 91052 Erlangen, Germany. 


\section{Modelling and analysis of $y / 36^{\circ}$-cut lithium niobate/epoxy piezocomposite transducers, tested at room temperature}

\subsection{Properties of lithium niobate and the aim of the modelling work}

Lithium niobate piezoelectric material is obtained in the form of a single crystal, so there is a choice to be made between different crystal cuts in order to access the most appropriate piezoelectric properties. This is similar to the situation for quartz $z^{[14]}$. For bulk acoustic waves, longitudinal mode, a choice can be made between $\mathrm{z}$-cut and $\mathrm{y} / 36^{\circ}$ wafers. Plates with $\mathrm{y} / 36^{\circ}$ orientation electroded on the top and bottom faces have the highest piezoelectric efficiency. However, they produce an asymmetric ultrasonic beam profile. A comparison of beam profiles for $z$-cut and $y / 36^{\circ}$ material can be found in the following references: beam profile of single element of lithium niobate monolithic array ${ }^{[15]}$; steered-beam directivity plots measured on a steel half-cylinder for lithium niobate monolithic phased arrays ${ }^{[16]}$; and lithium niobate piezocomposite phased arrays operated on a steel test-block using an array controller in sector scan mode ${ }^{[10]}$.

For this part of the work, lithium niobate 1-3 piezocomposites using $y / 36^{\circ}$-cut material were made with epoxy filler and tested at room temperature. Epoxy filler was used for better comparison with established results for PZT/epoxy composites and for convenience in fabricating multiple test samples. The aim of the modelling and analysis work was to determine to what extent $y / 36^{\circ}$ lithium niobate piezocomposites follow the design rules commonly used in standard piezocomposite design, in particular the requirement of the pillar aspect ratio (PAR), pillar height/pillar width, for square pillars to be greater than $3: 1^{[17]}$. The primary reason for the criteron in the case of lithium niobate is to reduce the occurrance of unwanted resonant modes around the operating frequency, which may interfere with the operation of the transducer. Modelling and experiments have suggested that pillar aspect ratios higher than 3:1 are required to achieve a single mode response in lithium niobate. However, to produce high PAR piezocomposites requires narrower pillars and smaller kerfs (to maintain the volume fraction), resulting in a corresponding increase in the difficulty of manufacture. This is why it is advantageous to be able to work with low PAR structures if possible.

Transducer designers making piezocomposites using PZT piezoceramic can expect to obtain a 20-40\% increase in $k_{t}$ compared to bulk piezoceramic. We showed previously ${ }^{[18]}$ for $\mathrm{z}$-cut lithium niobate that the Smith and Auld model ${ }^{[19]}$ predicts that the thickness mode coupling coefficient for lithium niobate piezocomposite remains at or below $k_{t}$ for bulk single crystal. This agreed with the $k_{t}$ obtained from finite element simulations.

\subsection{Fabrication of the lithium niobate/epoxy piezocomposites}

$10 \times 10 \mathrm{~mm}^{2}$ piezocomposite samples were fabricated from an initial $4 \mathrm{~mm}$-thick $\mathrm{y} / 36^{\circ}$ lithium niobate plate by the 'dice and fill' method $^{[20]}$ using a dicing saw (Logitech Ltd, Model 15, diamond and wire disc saw). The pillars were backfilled with Araldite CY1301/HY1300 hard-setting epoxy. The piezocomposites had a $30 \%$ volume fraction (v.f.), a pillar width of $0.35 \mathrm{~mm}$, a kerf width of $0.29 \mathrm{~mm}$, a pillar aspect ratio (PAR, pillar height/pillar width) of 3, 4 and 6 and a nominal thickness of $1.05 \mathrm{~mm}, 1.40 \mathrm{~mm}$ and $2.10 \mathrm{~mm}$, respectively, with expected resonance frequencies of 1-3 MHz. Note that samples of different PAR originated from the same starting material and the pillar height was reduced accurately to the required thickness by lapping.

\subsection{Finite element modelling of the lithium niobate/epoxy piezocomposites}

Finite element modelling was carried out in PZFlex (Weidlinger Associates Inc) to obtain plots of impedance magnitude and phase against frequency for comparison with the experimental results. Full details of the modelling have been given in ${ }^{[17]}$. The most important difference in modelling lithium niobate piezocomposites, compared to piezocomposites made using PZT piezoceramic, is that lithiun niobate is in a single-crystal form and is highly anisotropic. In terms of crystal symmetry, lithium niobate belongs to the trigonal $3 m$ class of crystalline piezoelectric materials (see, for example, Berlincourt et al ${ }^{[21]}$ ), requiring six elastic, four piezoelectric and two dielectric parameters for a full three-dimensional model. (PZT ceramic material, on the other hand, is class $\infty m$ and only requires two elastic, three piezoelectric and two dielectric coefficients.) In this case, the lithium niobate parameters obtained by Kovacs et al were used $^{[22]}$.

Piezocomposite simulations for PZT ceramic can utilise a quarter pillar unit cell model with symmetrical boundary conditions. However, for a full treatment of lithium niobate piezocomposites in a $y / 36^{\circ}$ orientation, a full pillar unit cell was simulated, with translational boundary conditions, consisting of a square tapered pillar (taper angle $1-2^{\circ}$ ) of average measured dimensions from Table 1, plus the surrounding passive matrix. Meshing the model on a skewed conforming $\operatorname{mesh}^{[23]}$ produced a more realistic representation of the tapered pillars than using Cartesian elements, but did not have a significant effect on the results for resonance frequency and impedance magnitude for a pillar aspect ratio greater than 3.

Table 1. Average measured dimensions $(\mu \mathrm{m})$ of $y / 36^{\circ}$-cut, $30 \%$ v.f. piezocomposites, and standard deviation $(\sigma)$ on the measurements. Pillars are a square-based truncated pyramid shape

\begin{tabular}{c|c|c|c|c|c|c|}
\hline \multirow{2}{*}{$\begin{array}{c}\text { Measured } \\
\text { dimensions } \\
(\mu \mathrm{m})\end{array}$} & \multicolumn{2}{|c|}{ PAR 3 } & \multicolumn{2}{c|}{ PAR 4 } & \multicolumn{2}{c|}{ PAR 6 } \\
\cline { 2 - 8 } & $\begin{array}{c}\text { Pillar } \\
\text { width }\end{array}$ & $\begin{array}{c}\text { Kerf } \\
\text { width }\end{array}$ & $\begin{array}{c}\text { Pillar } \\
\text { width }\end{array}$ & $\begin{array}{c}\text { Kerf } \\
\text { width }\end{array}$ & $\begin{array}{c}\text { Pillar } \\
\text { width }\end{array}$ & $\begin{array}{c}\text { Kerf } \\
\text { width }\end{array}$ \\
\hline Top & 440 & 216 & 438 & 210 & 424 & 224 \\
\hline Bottom & 462 & 178 & 471 & 167 & 479 & 174 \\
\hline$\sigma$ & 31 & 11 & 34 & 12 & 72 & 13 \\
\hline
\end{tabular}

\subsection{Experimental and simulated results for the lithium niobate/epoxy piezocomposites}

For each of the samples, the impedance spectrum and the pulseecho response were measured. The impedance magnitude and phase spectra were obtained using an impedance analyser, Agilent model 4294A (Agilent Technologies, South Queensferry, UK). Samples were electroded on both sides and operated in air.

Figure 1 shows impedance spectra for the samples, compared to the results from finite element modelling for full (main picture) and quarter unit cell (inset) models. In both the experiment and model, the PAR 6 structure shows a single resonance 
mode. It can be seen that, for PAR 3 and 4, both the full unit cell model and experimental results show the appearance of additional modes that begin to interfere with the fundamental thickness mode in the piezocomposite. The fundamental mode in the experimental results for the PAR 3 piezocomposite is substantially less pronounced than the simulated results; however, it retains a broadband response. Similar behaviour at a low PAR and low volume fraction (30\%) was seen for $\mathrm{z}$-cut lithium niobate piezocomposite $^{[18]}$.

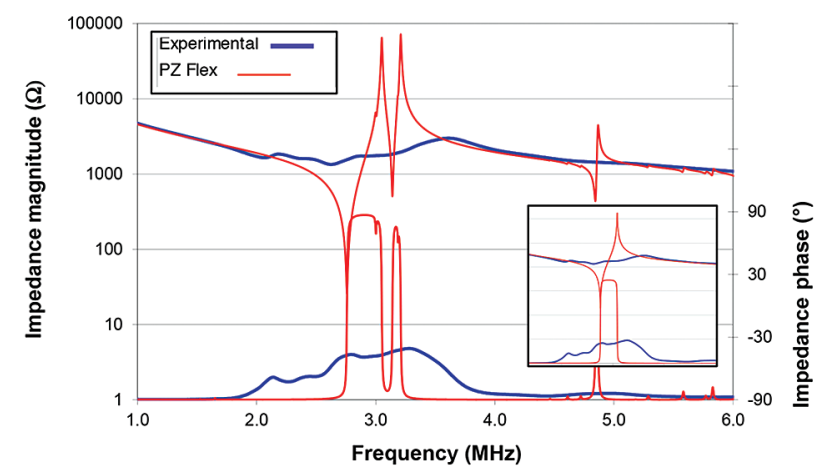

(a)

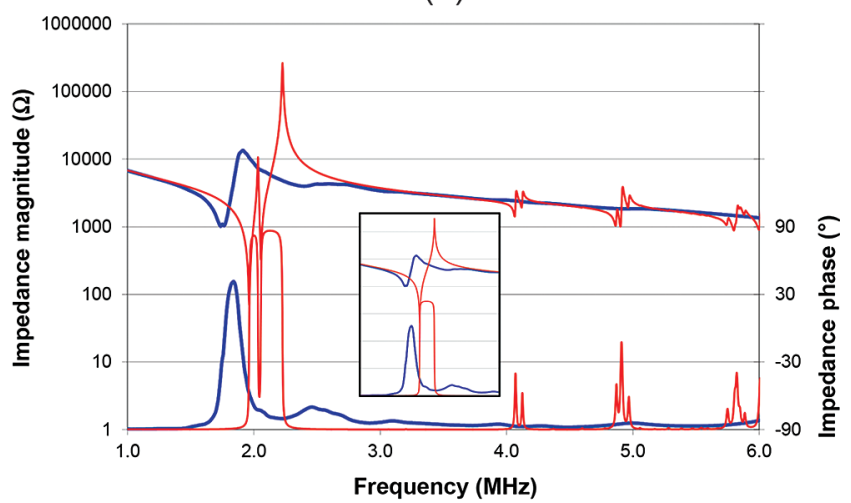

(b)

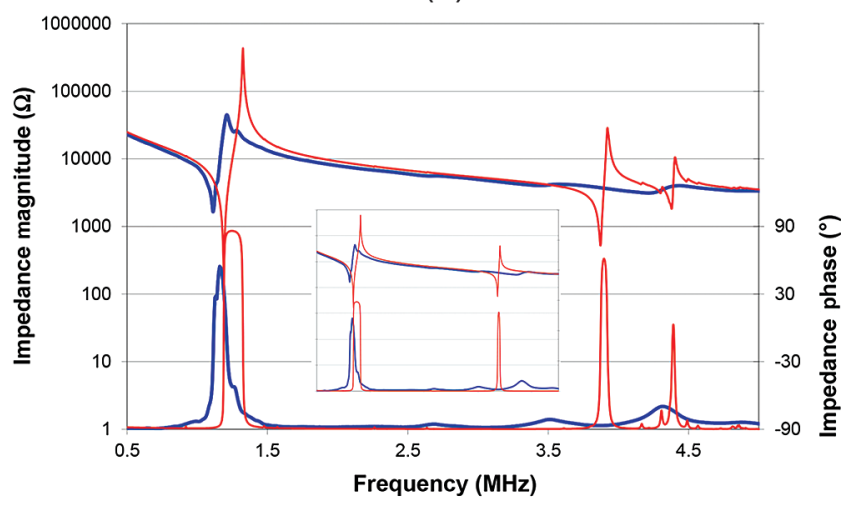

(c)

Figure 1. Experimental (thick line) and simulated full unit cell (fine line) electrical impedance magnitude and phase for $y / 36^{\circ}$-cut lithium niobate piezocomposites with v.f. $30 \%$ and a PAR of: (a) 3; (b) 4; and (c) 6. Insets show the results for the quarter unit cell model of piezocomposite, compared to the same experimental results

A key parameter of interest for a piezocomposite is the thickness mode coupling coefficient $k_{t}$. For the case of a slab of material electroded on the top and bottom faces, $k_{t}$ is estimated from the impedance magnitude curves using the series and parallel resonance frequencies $f_{s}$ and $f_{p}$ (Equation (1) $)^{[21]}$ :

$$
k_{t}^{2}=\frac{\frac{\pi}{2} \frac{f_{s}}{f_{p}}}{\tan \left(\frac{\pi}{2} \frac{f_{s}}{f_{p}}\right)}
$$

Experimental and simulated $k_{t}$ values are compared in Figure 2. The form of the experimental impedance curve for PAR 3 did not allow the calculation of $k_{t}$, since it was impossible to choose values for $f_{s}$ and $f_{p}$. Simulated results were taken from the single resonance occuring in the quarter unit cell models and the dominant resonance in the full unit cell models. Results from the models and experiment are within $10-20 \%$ of the standard value for bulk lithium niobate of $\mathrm{y} / 36^{\circ}$-cut orientation, which is $0.49^{[4,24]}$.

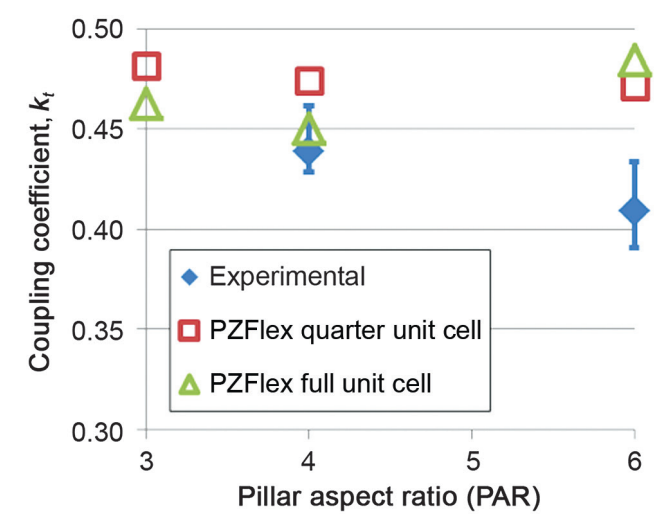

Figure 2. Electromechanical coupling coefficient $\boldsymbol{k}_{t}$ versus PAR from experimental and simulated (quarter unit cell and full unit cell models) impedance results for $y / 36^{\circ}$-cut lithium niobate piezocomposite, $30 \%$ v.f.

For the pulse-echo tests, the piezocomposites were clamped using screw-down clamps onto a $37 \mathrm{~mm}$-thick mild steel block. Measurements were made using a DPR300 ultrasonic pulserreceiver (JSR Ultrasonics, Imaginant Inc, Pittsford, NY). The return signal was low-pass filtered with a cut-off frequency of $10 \mathrm{MHz}$ and the first backwall echo was fast Fourier transformed to obtain the bandwidth. The results obtained show broad agreement with the electrical impedance results. Figure 3 shows (a) the $6 \mathrm{~dB}$ bandwidth and (b) the bandwidth normalised to the centre frequency (fractional bandwidth) for $\mathrm{y} / 36^{\circ}$-cut piezocomposite compared to z-cut piezocomposite of two different volume fractions, $30 \%$ and $45 \%$. Overall, $\mathrm{y} / 36^{\circ}$-cut lithium niobate piezocomposites were expected to have a broader bandwidth than $\mathrm{z}$-cut piezocomposites due to a larger efficiency. This was found for PAR 3-4, but the bandwidth decreased with increasing PAR.

\section{Fabrication and high-temperature testing of lithium niobate/cement piezocomposite}

\subsection{Fabrication}

In this part of the work, new piezocomposite samples were fabricated using a high-temperature cement matrix instead of epoxy in order to carry out high-temperature tests. As before, the dice and fill method ${ }^{[20]}$ was used. A lithium niobate crystal, $y / 36^{\circ}$ oriented, with starting dimensions of $13 \times 13 \times 1.5 \mathrm{~mm}^{3}$, was diced using an automatic dicing saw (DAD 3230, Disco Corp) specified with a depth accuracy of $\pm 1 \mu \mathrm{m}$ and a positioning accuracy of $\pm 3 \mu \mathrm{m}$. 


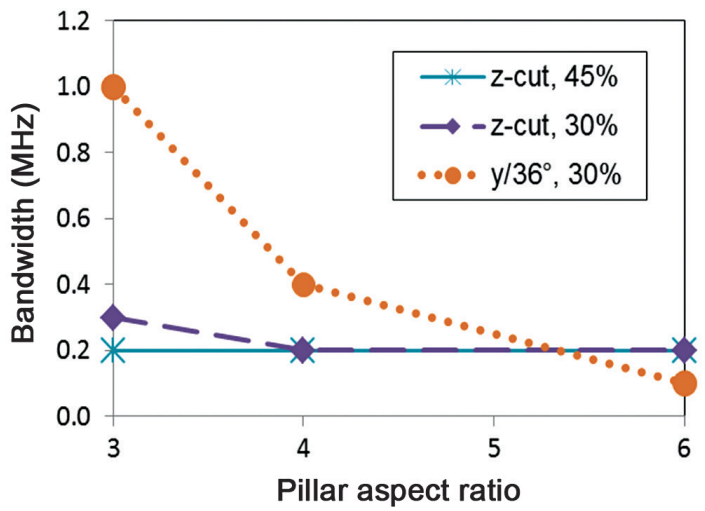

(a)

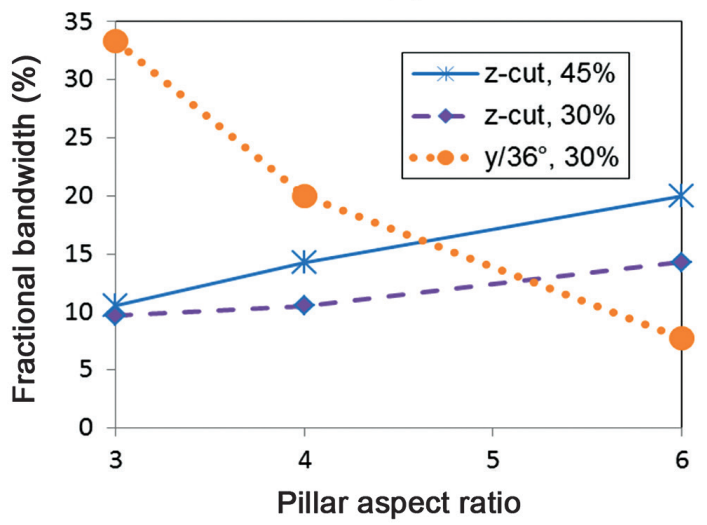

(b)

Figure 3. Bandwidth versus function of PAR for $y / 36^{\circ}$-cut (v.f. 30\%) and z-cut (v.f. $30 \%, 45 \%$ ) lithium niobate piezocomposite: (a) bandwidth in $\mathrm{MHz}$; (b) normalised to centre frequency. (Note that the centre frequency decreases with increasing PAR, from $2.5 \mathrm{MHz}$ to $1 \mathrm{MHz}$ )

The saw cut depth was $1 \mathrm{~mm}$ and cuts were made $1.3 \mathrm{~mm}$ apart. A saw blade thickness of $0.5 \mathrm{~mm}$ was used, with the gap between the pillars (kerf) expected to be slightly larger. The maximum available kerf width was used to facilitate adding the passive material in between the pillars. These dimensions give a volume fraction of lithium niobate of $30-40 \%$ and a PAR of 1-1.3. Superior-quality diced material could be produced using the automated saw, as shown in Figure 4(a).

Two high-temperature ceramic adhesives/potting compounds were tried for the piezocomposite filler material. Both were specified to more than $1000^{\circ} \mathrm{C}$ and comprised a powder and a liquid binder mixed to a paste. Initially, alumina cement (Durapot 801, Cotronics Corp) was tried as a passive material but, unfortunately, it degraded in water and tended to disintegrate during lapping, as seen in Figure 4(b). Zirconia cement (Resbond 940, Cotronics Corp) proved to be a much better passive material, as shown in Figure 4(c).

The diced sample with lithium niobate pillars was filled from the front face with zirconia-based cement and then placed in a vacuum oven. A vacuum created in the oven and then released helps to push the cement into the kerfs to fill the sample properly. The oven temperature was raised to $50^{\circ} \mathrm{C}$ and the sample was left overnight to cure. Excess lithium niobate and filler material on the top and bottom surfaces was removed by lapping to the desired final sample thickness using an aqueous suspension of $9 \mu \mathrm{m}$ aluminium oxide powder as the grinding medium. The sample was mounted for lapping onto a glass sample holder with removable wax (melting temperature about $60^{\circ} \mathrm{C}$ ). Front and back electrodes were made with silver paint (PELCO
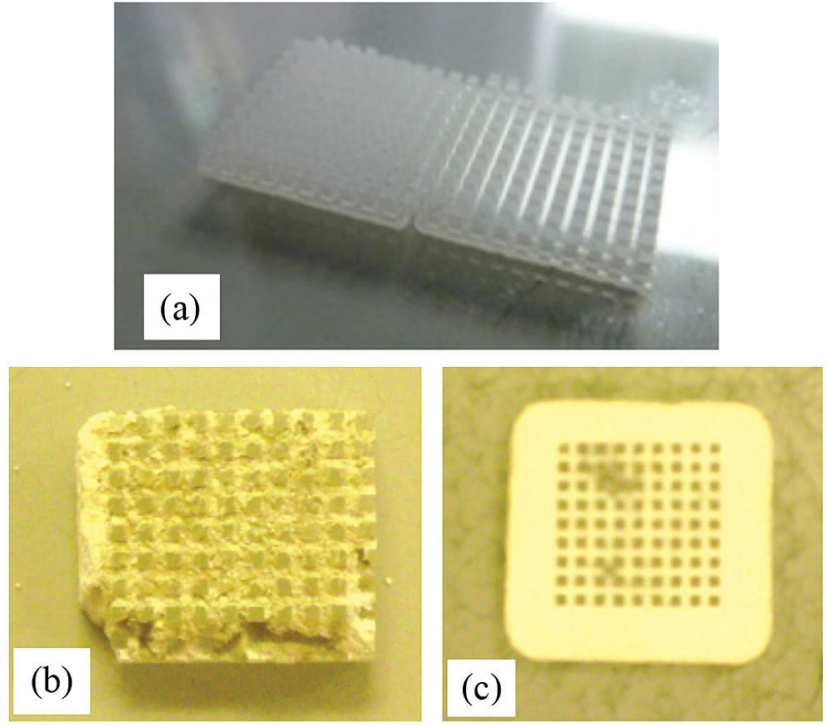

Figure 4. Lithium niobate and piezocomposite samples $13 \times 13 \mathrm{~mm}^{2}$ : (a) diced lithium niobate; (b) piezocomposite with alumina cement; (c) piezocomposite with zirconia cement

high-performance silver paste, Ted Pella Inc), which was rated up to $900^{\circ} \mathrm{C}$ and found to perform well in this application up to $500^{\circ} \mathrm{C}$.

\subsection{High-temperature tests on lithium niobate single crystal and piezocomposite}

Lithium niobate single crystal was heated in air to a temperature up to $500^{\circ} \mathrm{C}$ over a series of cycles, each lasting 2-3 h. After each annealing cycle, the sample was cooled and the X-ray diffraction pattern was obtained. Figure 5 shows peaks at $23.8^{\circ}$ and $48.5^{\circ}$, which remained stable throughout the tests. This indicates no change in crystal structure for the lithium niobate throughout the annealing sequence.

Figure 6 shows the electrical impedance magnitude measured during heating on a hot plate to $500^{\circ} \mathrm{C}$ in steps of $100^{\circ} \mathrm{C}$ for (a) lithium niobate single crystal and (b) lithium niobate piezocomposite, PAR 1.2. It can be seen that the lithium niobate piezocomposite does not exhibit lateral modes below the thickness mode resonance. For lithium niobate single crystal the resonance frequency remained stable to within $0.1 \mathrm{MHz}$ on heating to $500^{\circ} \mathrm{C}$, and for lithium niobate piezocomposite the resonance frequency remained within $0.2 \mathrm{MHz}$ up to $400^{\circ} \mathrm{C}$.

The peak values of impedance magnitude for single crystal and piezocomposite samples at different elevated temperatures up to $400-500^{\circ} \mathrm{C}$ (extracted from the graphs of Figure 6) are shown in Figure 7. It is interesting to note that the peak impedance of lithium niobate piezocomposite goes up with increased temperature, whereas the peak impedance of the single-crystal material goes down. We suggest that for the single crystal there is an increase in damping in the material at high temperatures, whereas in the piezocomposite a decrease of damping in the cement due to curing is the dominant effect. For both single crystal and piezocomposite the electromechanical coupling coefficient, $k_{t}$, remained constant to within 3\% during heating.

Further experiments were carried out on two piezocomposite samples (both $12 \times 12 \times 1 \mathrm{~mm}^{3}$, pillar width $0.8 \mathrm{~mm}$, pitch $1.3 \mathrm{~mm}$, PAR 1.2 and volume fraction $38 \%$ ) subjected to thermal cycling on a hot plate from room temperature to elevated temperatures up to $500^{\circ} \mathrm{C}$. The electromechanical coupling coefficient, $k_{t}$, was measured 


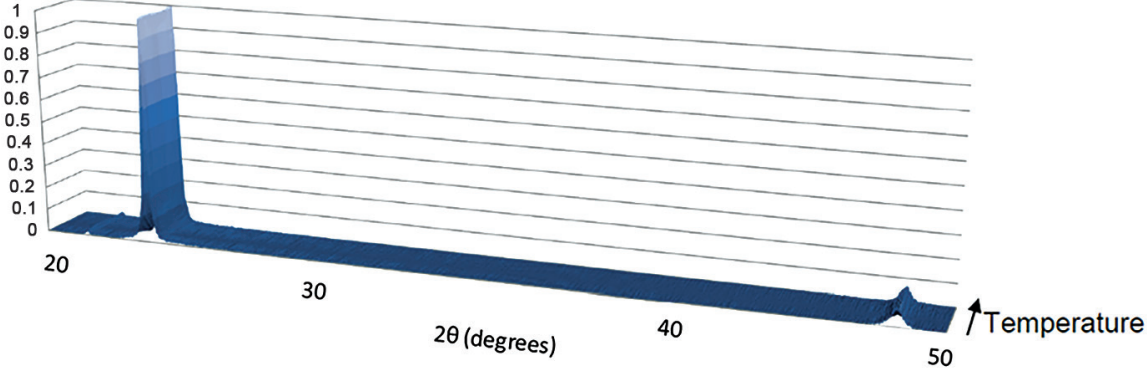

Figure 5. X-ray diffraction pattern measured at room temperature for lithium niobate single crystal after annealing cycles to $100^{\circ} \mathrm{C}, 200^{\circ} \mathrm{C}, 300^{\circ} \mathrm{C}, 400^{\circ} \mathrm{C}$ and $500^{\circ} \mathrm{C}$

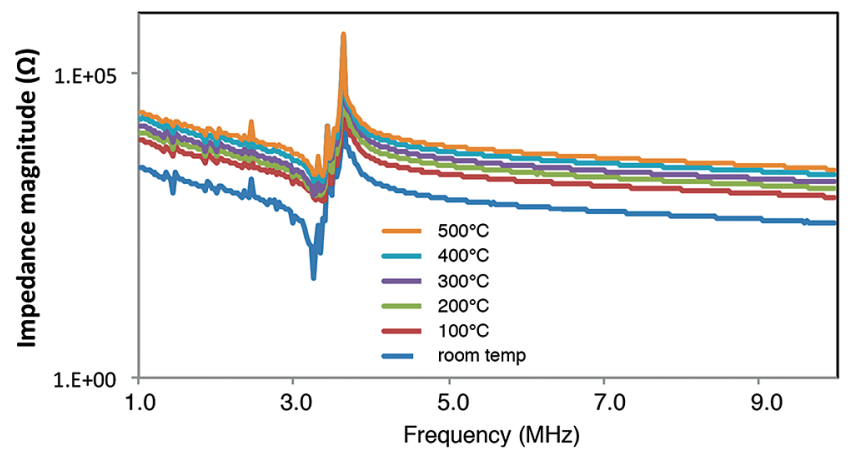

(a)

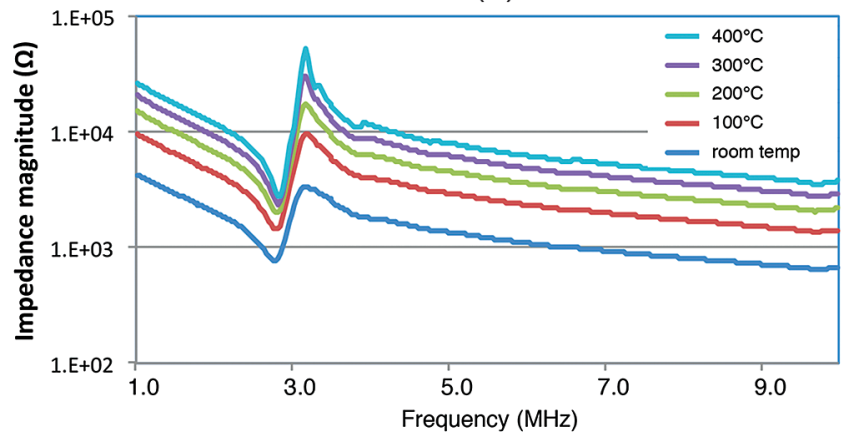

(b)

Figure 6. Impedance magnitude versus frequency measured at elevated temperatures: (a) single-crystal lithium niobate up to $500^{\circ} \mathrm{C}$; (b) lithium niobate piezocomposite PAR 1.2, v.f. $38 \%$, up to $400^{\circ} \mathrm{C}$. In both cases, the lowest curve is for room temperature and the uppermost curve is for the highest temperature recorded

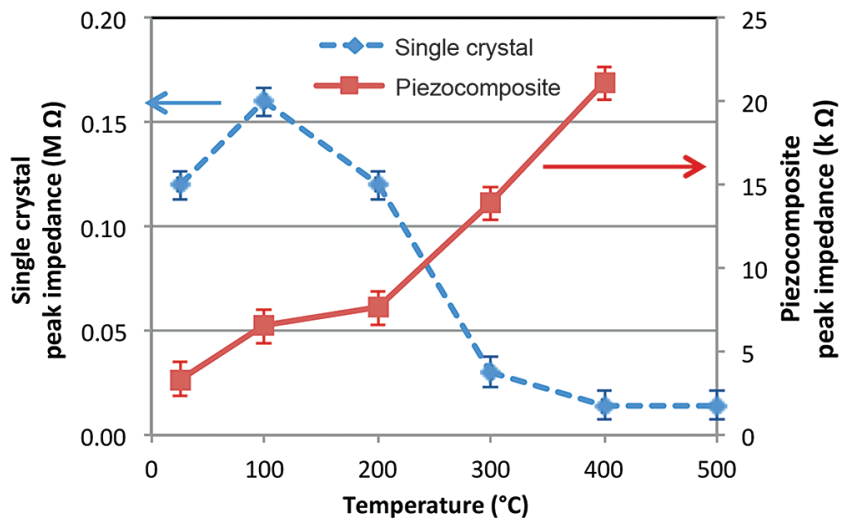

Figure 7. Peak impedance magnitude versus temperature for lithium niobate single crystal and lithium niobate piezocomposite, extracted from the impedance curves of Figure 6 at room temperature after cycles up to $100^{\circ} \mathrm{C}$ $200^{\circ} \mathrm{C}, 300^{\circ} \mathrm{C}, 400^{\circ} \mathrm{C}$ and $500^{\circ} \mathrm{C}$ (Figure 8). For Sample $1, k_{t}$ remained constant to within $6 \%$ but Sample 2 cracked on cooling from $300^{\circ} \mathrm{C}$, causing a large reduction in $k_{t}$. The cause of the cracking is believed to be a build-up of stress on cooling due to the pyroelectric effect in lithium niobate.

\section{High-temperature lithium niobate piezocomposite transducer}

\subsection{Transducer design and manufacture}

A lithium niobate piezocomposite transducer for high-temperature ultrasonic testing was designed with an operating frequency range of 2.6-3.3 MHz. A lithium niobate single-crystal plate was diced into pillars and filled with zirconia cement, as described earlier (Section 3.1). After curing and electroding the piezocomposite, the device was fabricated with a steel case and the same zirconia cement was used as a backing layer. No matching layer was used. The piezocomposite characteristic dimensions were: volume fraction 33\%, pillar height $1 \mathrm{~mm}$ and pillar width $0.8 \mathrm{~mm}$, giving a PAR of 1.25. The overall dimensions of the piezocomposite used to fabricate the transducer were $13 \times 13 \times 1 \mathrm{~mm}^{3}$. Figure 9 shows

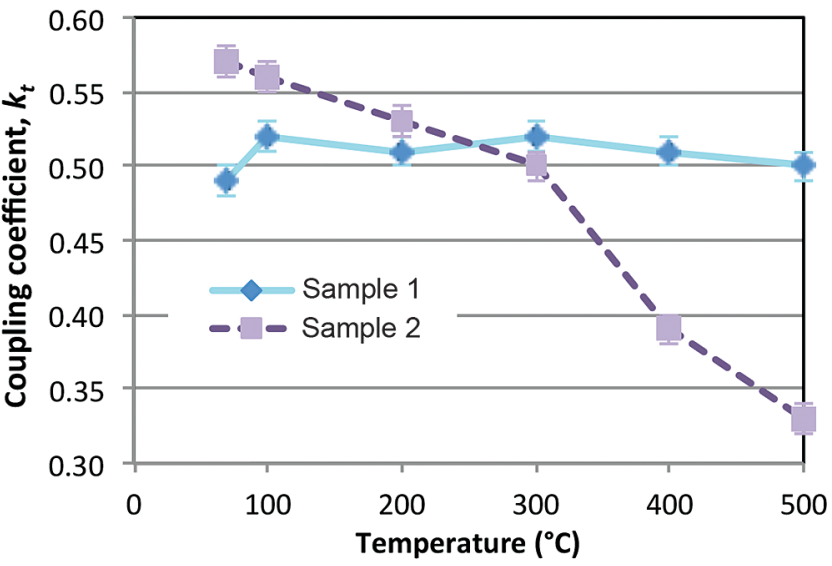

Figure 8. Coupling coefficient versus annealing temperature for two lithium niobate piezocomposite samples, heated on a hot plate and measured after cooling from each temperature. Sample 1 showed very good stability over the measurement, but Sample 2 cracked on cooling down from $300^{\circ} \mathrm{C}$

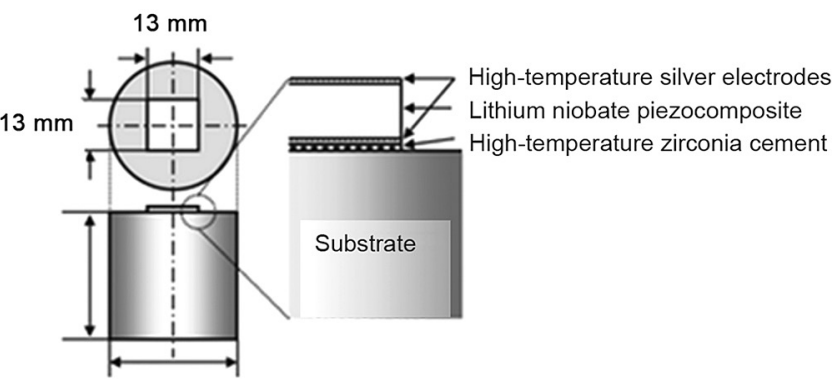

Figure 9. Design of transducer for high-temperature ultrasonic testing 
the transducer design and Figure 10(a) shows the finished transducer.

From the impedance magnitude characteristic in Figure 10(b), we can obtain the series and parallel resonance frequencies of $2.7 \mathrm{MHz}$ and $3.1 \mathrm{MHz}$, respectively. The operating frequency of the transducer obtained from the backwall echo signal was 3.2 $\mathrm{MHz}$.

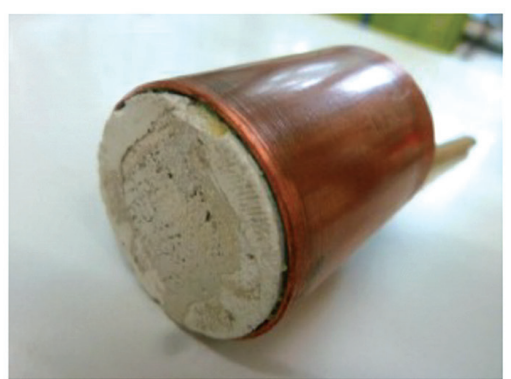

(a)

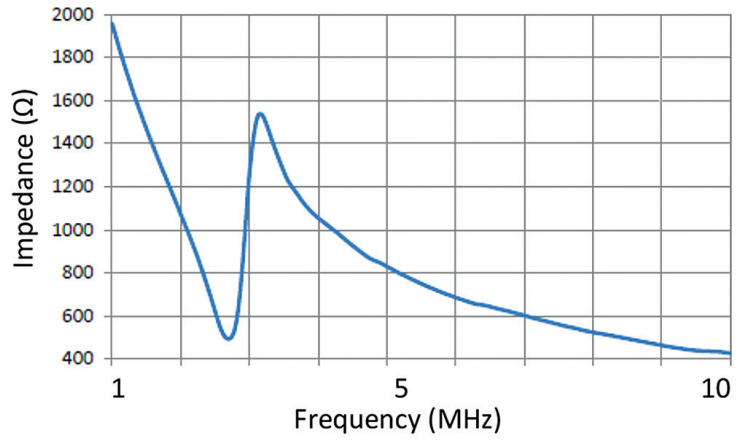

(b)

Figure 10. (a) Photograph of finished transducer; (b) impedance magnitude

\subsection{Pulse-echo testing at room temperature and $400^{\circ} \mathrm{C}$}

The transducer was tested on a $30 \mathrm{~mm}$-thick steel block, longitudinal sound velocity $5980 \mathrm{~ms}^{-1}$, with two side-drilled holes at $10.7 \mathrm{~mm}$ and $16.8 \mathrm{~mm}$ depth below the top surface, as shown in Figures 11(a) and 11(b). Pulse-echo results at room temperature using Soundsafe couplant (Diagnostic Sonar Ltd) show detection of the $16.8 \mathrm{~mm}$ depth hole at $7 \mu$ s and $17 \mu$ s, as shown in Figures 11(c) and 11(d). The first $3 \mu$ s of the main bang is not shown.

Three couplants were used to cover the temperature range up to $400^{\circ} \mathrm{C}$. Soundsafe couplant can withstand $140^{\circ} \mathrm{C}$ and was used at $100^{\circ} \mathrm{C}$. In the range $200-300^{\circ} \mathrm{C}$, an 'anti-seize' copper-based grease was used. Although this is not an official high-temperature couplant, it worked in the range of $200-300^{\circ} \mathrm{C}$. For the target temperature of $400^{\circ} \mathrm{C}$, Sono 900 ultrasonic couplant (Sonotech Inc) was used. This is a thick, gritty paste specified for $315-480^{\circ} \mathrm{C}$. We found that this performed well and produced less fumes than Sono 1200 (Sonotech

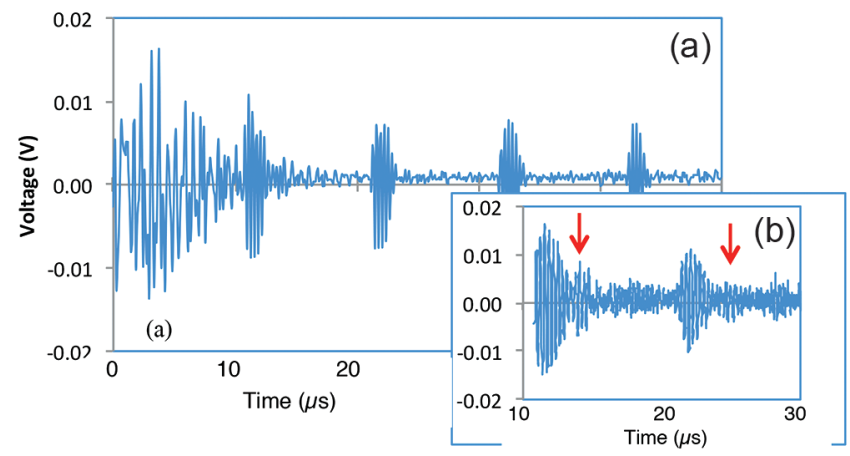

Figure 12. Pulse-echo response of piezocomposite transducer on steel block at $400^{\circ} \mathrm{C}$ : (a) no flaw; (b) detection of hole, $10.7 \mathrm{~mm}$ depth, $3.6 \mu$ s after first backwall echo

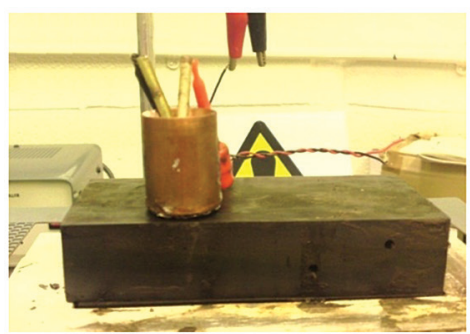

(a)

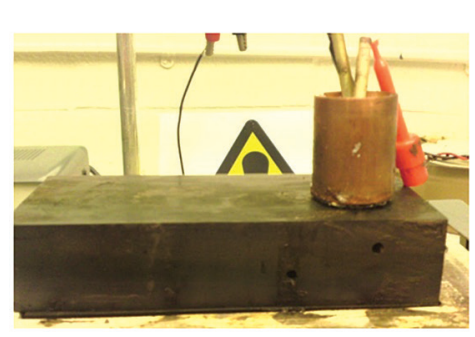

(b)

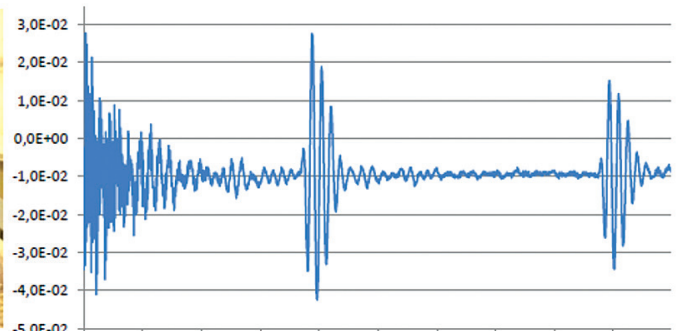

(c)

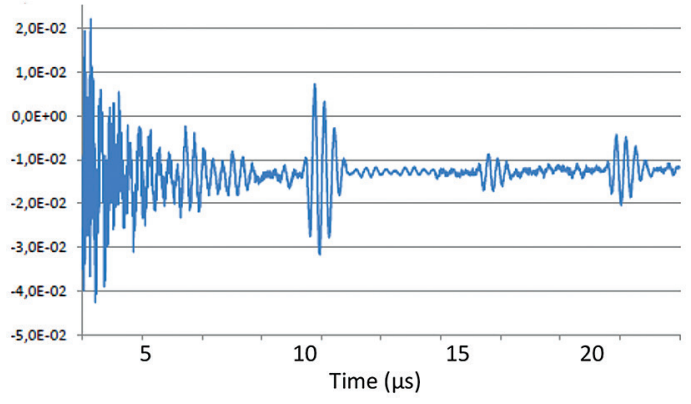

(d)

Figure 11. (a) and (b) Pulse-echo testing set-up on hotplate for $30 \mathrm{~mm}$ steel block with side-drilled holes: (a) backwall position and (b) side-drilled holes at $10.7 \mathrm{~mm}$ and $16.8 \mathrm{~mm}$ depth; (c) and (d) room temperature results for pulse-echo response: (c) backwall and (d) hole at $16.8 \mathrm{~mm}$ depth detected at $7 \mu \mathrm{s}$ with repeat reflection at $17 \mu \mathrm{s}$. First $3 \mu \mathrm{s}$ of main bang not shown

Inc, specified for $370-600^{\circ} \mathrm{C}$ ), which was also tested. At a hot plate temperature of $400^{\circ} \mathrm{C}$ the transducer was in good operational condition, as shown in Figure 12(a). Figure 12(b) shows detection of the hole at $10.7 \mathrm{~mm}$ depth, $3.6 \mu$ s after the first backwall echo. The large main bang prevented detection before the backwall echo.

\section{Conclusions}

We showed that high-temperature ultrasonic transducers can be made from $y / 36^{\circ}$ oriented lithium niobate 1-3 piezocomposites with a high-temperature cement matrix. We made a stand-alone encased transducer, which was fluid-coupled to the test-block using high-temperature couplant. Using hightemperature couplant it was possible to detect a side-drilled hole in the block at $400^{\circ} \mathrm{C}$, albeit with a weak indication. The piezocomposite material itself was characterised at a high temperature by impedance measurements. A high piezocomposite thickness mode coupling coefficient, $k_{t}$, of $\sim 0.50$ was obtained from the lithium niobate/cement piezocomposites, similar to the standard bulk 
value for lithium niobate of 0.49 .

We conclude that lithium niobate piezocomposite can be used to make a stand-alone high-temperature transducer for thickness measurement and potentially for flaw detection. The piezocomposite material showed no deterioration at high temperatures and survived multiple thermal cycles. Although a pillar aspect ratio (PAR) of more than $3: 1$ is usually recommended for piezocomposites, the lithium niobate/cement samples showed a clear resonance mode at the expected frequency and satisfactory performance with a PAR as low as 1.2 , which enables easier transducer fabrication.

\section{References}

1. S P Kelly, I Atkinson, C Gregory and K J Kirk, 'Online ultrasonic inspection at elevated temperatures', Proceedings of the 2007 IEEE Ultrasonics Symposium, New York, USA, Vol 1-6, pp 904-908, 28-31 October 2007.

2. M Budimir, A Mohimi, C Selcuk and T-H Gan, 'Hightemperature NDE ultrasound transducers for condition monitoring of superheated steam pipes in nuclear power plants', Proceedings of the International Conference on Nuclear Energy for New Europe, Bovec, Slovenia, 12-15 September 2011.

3. T R Shrout, R Eitel and C Randall, 'High-performance, hightemperature perovskite piezoelectric ceramics', In: Piezoelectric Materials in Devices, N Setter (Ed), Ch 19, p 417, 2002. ISBN 2 970034603.

4. S E Burrows, K L McAughey, R S Edwards and S Dixon, 'Solgel prepared bismuth titanate for high-temperature ultrasound transducers', RSC Advances, Vol 2, pp 3678-3683, 2012. DOI: 10.1039/C2RA20243C; see also K L McAughey, R S Edwards and S Dixon, 'Investigation into the use of bismuth titanate as a high-temperature piezoelectric transducer', 18th World Conference on Non-Destructive Testing, Durban, South Africa, 16-20 April 2012.

5. J Bennett, A J Bell, T J Stevenson and T P Comyn, 'Tailoring the structure and piezoelectric properties of $\mathrm{BiFeO}_{3}-\left(\mathrm{K}_{0.5} \mathrm{Bi}_{0.5}\right)$ $\mathrm{TiO}_{3}-\mathrm{PbTiO}_{3}$ ceramics for high-temperature applications, Applied Physics Letters, 103, 152901, 2013. http://dx.doi. org/10.1063/1.4824652

6. J R Fothergill, P Willis and S Waywell, 'Development of hightemperature ultrasonic transducers for under-sodium viewing applications', British Journal of Non-Destructive Testing, Vol 31, pp 259-264, 1989.

7. G Shepherd, A Cochran, K J Kirk and A McNab, '1-3 connectivity composite material made from lithium niobate and cement for ultrasonic condition monitoring at elevated temperatures', Ultrasonics, Vol 40, pp 223-226, 2002.

8. A Baba, C T Searfass and B R Tittmann, 'High-temperature ultrasonic transducer up to $1000^{\circ} \mathrm{C}$ using lithium niobate single crystal', Applied Physics Letters, 97, 232901, 2010. DOI: $10.1063 / 1.3524192$

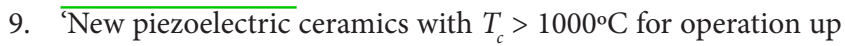
to $800^{\circ} \mathrm{C}$, BRITE/EURAM2, December 1992-November 1995, led by Ferroperm Piezoceramics A/S, Project \#BRE20254; see also 'Non-destructive testing at $800^{\circ} \mathrm{C}$ ', http://ec.europa.eu/ research/success/en/mat/0041e.html

10. N Schmarje, K J Kirk and S Cochran, 'Comparison of $y / 36^{\circ}{ }_{-}$ cut and $\mathrm{z}$-cut lithium niobate composites for high-temperature ultrasonic applications', Nondestructive Testing and Evaluation, Vol 20, No 2, pp 77-87, 2005.

11. $\mathrm{K} \mathrm{J} \mathrm{Kirk,} \mathrm{N} \mathrm{Schmarje} \mathrm{and} \mathrm{S} \mathrm{Cochran,} \mathrm{'Lithium} \mathrm{niobate}$ piezocomposite phased arrays operating at high temperatures', Insight, Vol 46, No 11, pp 662-665, 2004.

12. N Schmarje, K J Kirk and S Cochran, '1-3 connectivity lithium niobate composites for high-temperature operation', Ultrasonics, Vol 47, pp 15-22, 2007.

13. K J Kirk, C W Scheit and N Schmarje, 'High-temperature acoustic emission tests using lithium niobate piezocomposite transducers', Insight, Vol 49, No 3, pp 142-145, 2007.

14. R E Newham, Properties of Materials - Anisotropy, Symmetry, Structure, p 101, Oxford University Press, 2005. ISBN 019 852076-x.

15. A McNab and I Stumpf, 'Monolithic phased array for the transmission of ultrasound in NDT ultrasonics', Ultrasonics, Vol 24, No 3, pp 148-155, 1986.

16. K J Kirk, A McNab, A Cochran, I Hall and G Hayward, 'Ultrasonic arrays for monitoring cracks in an industrial plant at high temperatures', IEEE Transactions on Ultrasonics, Ferroelectrics, and Frequency Control, Vol 46, pp 311-319, 1999.

17. W A Smith, 'The role of piezocomposites in ultrasonic transducers', IEEE Proceedings Ultrasonics Symposium, pp 755-766, 1989.

18. K J Kirk and N Schmarje, 'Experimental and simulated performance of lithium niobate 1-3 piezocomposites for $2 \mathrm{MHz}$ non-destructive testing applications', Ultrasonics, http://dx.doi. org/10.1016/j.ultras.2012.05.007

19. W A Smith and B A Auld, 'Modelling 1-3 composite piezoelectrics: thickness-mode oscillations', IEEE Transactions on Ultrasonics, Ferroelectrics, and Frequency Control, Vol 38, pp 40-47, 1991.

20. R E Newnham, D P Skinner and L E Cross, 'Connectivity and piezoelectric-pyroelectric composites', Materials Research Bulletin, Vol 13, pp 525-536, 1978.

21. D A Berlincourt, D B Curran and H Jaffe, 'Piezoelectric and piezomagnetic materials and their function in transducers', In: Physical Acoustics Vol I, Part A, W P Mason (Ed), Ch 3, p 230, Academic Press, London, 1964.

22. G Kovacs, $M$ Anhorn, $H$ E Engan, $G$ Visintini and C C W Ruppel, 'Improved material constants for lithium niobate and lithium tantalate, Proceedings of the 1990 IEEE Ultrasonics Symposium, pp 435-438, 1990.

23. D Powell, P Reynolds, D Vaughan, J Mould and C Desilets, 'The impact of element taper and inhomogeneous material properties on ultrasonic array performance, Proceedings of the IEEE Ultrasonics Symposium, Vol 2, pp 1161-1166, 2002. DOI: 10.1109/ULTSYM.2002.1192500

24. S Zhang, R Xia and T R Shrout, 'Lead-free piezoelectric ceramics versus PZT?', Journal of Electroceramics, March 2007. DOI: $10.1007 / \mathrm{s} 10832-007-9056-\mathrm{Z}$ 